2016-07-02

\title{
Bullying: An Ecological Approach to Intervention in Schools
}

\author{
Hornby, Garry
}

http://hdl.handle.net/10026.1/5385

10.1080/1045988x.2015.1086969

Preventing School Failure: Alternative Education for Children and Youth

Informa UK Limited

All content in PEARL is protected by copyright law. Author manuscripts are made available in accordance with publisher policies. Please cite only the published version using the details provided on the item record or document. In the absence of an open licence (e.g. Creative Commons), permissions for further reuse of content should be sought from the publisher or author. 


\title{
Bullying: an ecological approach to intervention in schools
}

\author{
Garry Hornby
}

Institute of Education, University of Plymouth

This is an accepted manuscript of an article published by Routledge/Taylor and Francis in: Preventing School Failure, May 2016, 60(3), 222-230.

Available at: http://dx.doi.org/10.1080/1045988X.2015.1086969

Correspondence: Professor Garry Hornby, Institute of Education, Plymouth University, Drake Circus, Plymouth, Devon, UK, PL4 8AA

Email: garry.hornby@plymouth.ac.uk

\begin{abstract}
Bullying is major concern in education worldwide, particularly in countries like New Zealand that are reported to have high rates of bullying in schools. In this article it is proposed that, in order to effectively prevent or substantially reduce bullying in schools, a systemic approach needs to be adopted, with interventions organized at various levels. An ecological model for bullying prevention is presented which suggests strategies and interventions at the levels of teachers, schools, communities, and society. Examples of interventions that have been found in the literature to have evidence supporting their effectiveness have been outlined at each of these levels. Guidelines are presented for schools adopting such an ecological model for addressing bullying and for bringing about the changes needed to implement it successfully.
\end{abstract}

Key words: bullying, schools, research, ecological, interventions 
Bullying has been defined in various ways, including, "... aggressive behavior that intentionally harms another person.” (Atkinson \& Hornby, 2002, p. 187) and “... the systematic abuse of power in interpersonal relationships" (Rigby, 2008, p. 22). Bullying behavior can be covert or overt, physical, social, relational or digital. It has been linked with poor academic outcomes, long-term mental health issues, child suicides and school shootings, and therefore is a key issues for educators and other professionals who work in schools, such as psychologists and counselors (Bradshaw, 2015; Casebeer, 2012; Hymel \& Swearer, 2015; Jimerson, Swearer \& Espelage, 2010; Rigby, 2012).

Definitions of bullying behavior typically include four elements. First, bullying is deliberate - there is an intention to cause physical and/or psychological pain or discomfort to another person. Second, bullying involves a power imbalance - that is between the target and the initiator, which may be based on physical size, age, gender or social status. Third, bullying is typically not a one-time occurrence - it is repeated over time, with the threat of further incidents leading to fear and anxiety. Fourth, bullying is harmful - there is short or long-term physical or psychological harm to the target of the bullying (Goldstein, 2013; Hymel \& Swearer, 2015; MoE, 2014).

Bullying is generally considered to begin at the early childhood education level (Alsaker \& Gutzwiller-Helfenfinger, 2010) with its prevalence increasing during the elementary school years, typically peaking at middle school level, then declining through the high school years (Goodstein, 2013; Hymel \& Swearer, 2015; Rigby, 2008). However, bullying continues to be an issue in adulthood, with significant levels of workplace bullying and mobbing occurring, particularly in large institutions such as hospitals and universities (Worksafe New Zealand, 2014). Mobbing, which can be horizontal or vertical, can involve ganging up on someone, spreading rumors, isolating and excluding them, threatening or harassing them (Elliott, 2003).

Bullying tends to be male dominated, whereas mobbing tends to be female dominated (Garandeau, Wilson \& Rodkin, 2010). Male bullies tend to use physical bullying, females tend to use verbal or relational means (Goodstein, 2013). Bullies may have social adjustment problems or may be confident or popular children (Casebeer, 2012; Rigby, 2008). Targets of bullying tend to be different in some way: anxious, submissive, provocative, or have special educational needs or disabilities (Goodstein, 2013). Children with special needs or disabilities have been found to experience twice the levels of bullying than their typically developing peers, so are 
particularly vulnerable to the consequent physical harm and psychological distress that this can result in (Hartley, Bauman, Nixon \& Davis, 2015).

Bullying behavior is complex and can take many forms, including physical, verbal, and social or relational bullying (Rigby, 2008). Bullying behavior can be direct and easily observed or indirect and hidden. A great deal of bullying of children takes place in group situations and rarely occurs in front of adults (Casebeer, 2012; MoE, 2014).

Cyberbullying is a form of bullying that is enabled, enhanced, or mediated through digital technology (Smith \& Slonje, 2010; Snakenborg, Acker \& Gable, 2011). Digital technology can be a medium for all kinds of bullying behavior physical, verbal and social and relational. Cyberbullying is becoming more prevalent and involves using email, cell phones, chat rooms, social networking sites and instant messaging to bully others verbally, socially or psychologically (Couvillon \& Ilieva, 2011; Smith \& Slonje, 2010).

Reports from large scale surveys on the prevalence of bullying that occurs at least once per week range from three percent in Norway (Olweus, 1993), seven percent in the UK (Smith \& Sharp, 1994), eight percent in the USA (Nansel, Overpeck, Pilla, Ruan, Simons-Morgan \& Scheidt, 2001) to 16 percent in Australia (Rigby, 2008). A study of 13 year olds from 27 different countries (Krug, Dahlberg, Mercy, Zwi \& Lozano, 2002) found that one to ten percent were prepared to admit that that they engaged in bullying at least once a week but 12 to 64 percent admitted to sometimes engaging in bullying.

Bullying has detrimental effects on children's health, wellbeing and learning. Both targets and initiators of bullying are at increased risk for adverse long-term outcomes, including early school leaving (Atkinson \& Hornby, 2002; Bradshaw, 2015). Although most research in this area focuses on impacts on initiators and targets it is likely that bullying also impacts negatively on bystanders, who witness bullying, and upstanders, who intervene in attempts to stop bullying (Casebeer, 2012; Goodstein, 2013; Rigby, 2008). Students who are bullied are more likely to experience symptoms of depression and anxiety and to avoid going to school (Atkinson \& Hornby, 2002). Bullying that is particularly sustained, severe or intense may be linked to severe physical and mental health outcomes, including increased risk of suicide (Bradshaw, 2015;Goodstein, 2013). Addressing bullying effectively has benefits for the future of both targets and initiators of bullying as well as bystanders 
and upstanders.

Traditionally, bullying incidents have been managed through the use of punishment such as suspensions from school (Goodstein, 2013; Rigby, 2008). This approach focuses on students reporting incidents to adults, who take action to fix situations, which provides few opportunities for students to learn new ways to manage social behaviors (MoE, 2014). Research shows that many bullying incidents are not reported, and that students perceive schools not to be addressing their concerns, or that reporting bullying to teachers can make the bullying worse (Goodstein, 2013; MoE, 2014). Preferred approaches involve addressing bullying incidents through the use of problem-solving or conflict resolution processes that involves students and parents actively working with school staff to create solutions (MoE, 2014; Thompson \& Smith, 2011). These approaches are likely to result in fewer suspensions from school, which in the long-term supports better outcomes for vulnerable young people. These approaches take the view that supports and strategies need to be in place for both targets and initiators of bullying (Goldstein, 2013; MoE, 2014).

\section{Research on interventions to prevent bullying}

There has been extensive development of bullying prevention programs and considerable research on the effectiveness of these conducted in the past 30 years. The best known is the groundbreaking research by Olweus $(1993 ; 2010)$, conducted in Scandinavia in the 1980s, that reported reductions in bullying of around 50 percent. In contrast, a leading researcher on bullying recently commented that, "We have 67 bullying prevention programs none of which are working in the U.S." (Espelage, 2010, quoted in Goodstein, 2013, p. ix). Other researchers have found that the prevalence of bullying in schools has not shown substantial decreases despite the greatly increased awareness of its negative effects and the widespread application of bullying prevention programs (Hamarus \& Kaikkonen, 2008; Rigby \& Smith, 2011). Given the questions raised about the effectiveness of interventions to prevent bullying it is useful to consider what syntheses and meta-analyses of the research on bullying prevention programs reveal. There have been several of these major reviews of research which have drawn on studies conducted in many different countries, including the USA, although research in the USA has not dominated findings, as is often the case in such reviews of educational research.

In a synthesis of findings from an edited book (Smith, Pepler \& Rigby, 2004), 
comprising evaluations from several countries, of a wide range of interventions to reduce bullying, Rigby (2008) reported that most interventions produced average reductions in bullying of around 15 to 20 percent. Some interventions claimed success rates of around 50 percent but others were not able to show any significant improvements. The inconsistency of findings made it difficult to conclude which interventions were more effective, except that interventions that were thoroughly implemented with strong support from the school community were noted to result in better outcomes.

A meta-analysis of 16 studies of bullying interventions conducted from 1980 through 2004 found that interventions produced clinically important positive effects for about one-third of the outcome variables but that the majority of outcomes evidenced no meaningful change (Merrell, Gueldner, Ross \& Isava, 2008). The authors concluded that school bullying interventions may produce modest positive outcomes, but that they are more likely to influence knowledge, attitudes, and selfperceptions rather than actual bullying behaviors, and that the majority of outcome variables in intervention studies are not meaningfully impacted.

A meta-analysis of 44 evaluations of school-based anti-bullying programs was carried out including studies from 1983 to 2009 of which around one third were conducted in the USA and two thirds from the rest of the world (Ttofi \& Farrington, 2011). The report showed that, on average, bullying decreased by 20 to 23 percent and victimization decreased by 17 to 20 percent following the interventions. More intensive programs were more effective, as were programs including parent meetings, firm disciplinary methods, and improved playground supervision. However, the overall findings of this meta-analysis support the conclusion of Merrel, et al. (2008), that the impact of bullying interventions are typically modest.

A synthesis of findings of experimental evaluations of 17 anti-bullying programs for children and youth indicates that programs that involve parents were found to be more effective (Lawner \& Terzian, 2013). It also found that programs that used a whole-school approach to foster a safe and caring school climate, by training all teachers, administrators and school counselors to model and reinforce positive behavior and anti-bullying messages throughout the school year, were found to be effective. Mixed results were found for programs that included social and emotional learning, for example, self-awareness, relationship skills or responsible decisionmaking. 
The implication of the above analysis of research findings is that individual interventions and programs to prevent bullying vary in their effectiveness and are at best only modestly effective. This suggests the possibility that a different approach to bullying prevention is needed. In relation to this, Cushman and Clelland (2011, p.19), following their national survey of schools in New Zealand, have proposed that,

Bullying behavior is now conceptualized as a systemic phenomenon influenced by a wide range of risk and protective factors that relate to: the individual; family and peers; school environments; and community, cultural norms and media. As such, it needs a systemic solution.

This conclusion has been supported by other researchers on bullying such as Casebeer (2012) who suggests that, “... effective interventions require systematic, wholeschool initiatives (p. 165)."

Cushman and Clelland (2011) have also concluded that schools need to use comprehensive, whole- school approaches, with parents and community agencies forming an integral part of the solution. However, in their survey Cushman and Clelland found that very few New Zealand schools do this, which is a concern as New Zealand has been reported to have one of the highest rates of school-age bullying in the world (Harcourt \& Green, 2013).

The imperative from the research evidence for implementing more comprehensive approaches to bullying prevention is reinforced by a recent statement from Bradshaw (2015) who points out that, "The available research does suggest that multicomponent prevention approaches, which address different ecological layers and target multiple risk factors, are among the most effective... (p. 328)."

\section{Ecological model for bullying prevention}

The research findings summarized above suggest that specific anti-bullying interventions and programs are not sufficient individually to substantially impact bullying in schools, so it appears that a systemic approach is needed. In order to clarify the necessary components of potentially effective systemic approaches it is useful to take an ecological perspective, based on the work of Bronfenbrenner (1979). From this perspective, since bullying is impacted by influences from individuals, parents, peers, school, community and society, effective bullying prevention strategies and interventions need to be targeted at each of these levels. This means using an ecological model in order to plan and organize comprehensive programs for 
preventing bullying (Bradshaw, 2015; Espelage \& Swearer, 2010) in order to develop programs in which strategies and interventions are suggested at the levels of teachers, schools, communities and society, as discussed below.

\section{Teachers}

Goodstein (2013) suggests that there are many things that teachers can do to help prevent bullying. They can implement classroom principles on respectful relationships, including rules on the unacceptability of bullying. They can model relationship skills and assertive behaviors including non-violent methods of conflict resolution. They can make sure that they are approachable, good listeners and effective problem-solvers. Teachers can also identify possible targets and bullies and take effective action in each situation. Teachers can help children develop assertive responses to bullying and learn ways of accessing support from peers and adults. As Allen (2009) suggests, 'Changing a culture of bullying requires changing how adults respond to students (p. 200).'

Using co-operative learning structures and activities and class-wide peer tutoring regularly in lessons is a useful way to help children develop constructive interpersonal relationships (Crothers and Kolbert, 2010; Goldstein, 2013; MoE, 2014). Also, teaching aspects of Personal, Social and Health Education can be made an integral part of all subject areas (Craig, Pepler \& Blais, 2007). In addition, implementing specific evidence-based programs of social and emotional learning, such as Circle Time and Incredible Years Programs are excellent ways of creating a classroom culture that facilitates positive relationships and reduces the occurrence of bullying (Durlak, Weissberg, Dymnicki, Taylor \& Schellinger, (2011).

Circle Time is a technique developed and popularized by Jenny Mosely (Mosely, 1996) in England. It is typically used as a class-wide procedure, with children from pre-school to high school level, with everyone sitting in a circle. It has been found to promote positive relationships and a caring and respectful ethos in classrooms, as well as promoting the social and emotional development of children and facilitating development of high self-esteem and self-confidence (Canney \& Byrne, 2006; Miller \& Moran, 2007).

Incredible Years Programs have been developed by Carolyn Webster-Stratton in the USA (Webster-Stratton \& Reid, 2010). They consist of a set of linked 
comprehensive, and developmentally based programs targeting parents, teachers and children of up to 12 years of age and have been found to be effective in promoting children's social competence and reducing behavior problems (Drugli, Fossum, Larsson \& Morch, 2010; Fergusson, Horwood \& Stanley, 2013; Pidano \& Allen, 2015).

\section{Schools}

There are many things that schools can do to reduce and help prevent bullying. First and foremost, they can establish an ethos of caring and respect for others within the school through the active promotion of the attitudes and values that underpin these (Bradshaw, 2015; Orpinas \& Horne, 2010). Alongside their goals for promoting academic excellence schools need to have a commitment to creating safe and positive social environments in which children can flourish. They need to promote non-violent approaches to conflict resolution and have playground structures, games and supervision that facilitate positive interactions outside the classroom (Goodstein, 2013; MoE, 2014, Smith \& Sharp, 1994).

Rigby (2008 \& 2011) indicates that schools must acknowledge that bullying will be taking place, accept responsibility for addressing this, and believe that they can do something positive about it. Schools also need to work with students and parents to develop a comprehensive policy on bullying which clearly defines bullying, and disseminate this policy widely throughout the school and community. The policy should include a plan for action to reduce bullying as well as training for teachers to intervene appropriately when incidents occur. Implementation of the plan needs to be carefully monitored and its effectiveness regularly evaluated. Rigby also considers it important for schools to ensure that the curriculum informs students about bullying, promotes attitudes and values that help counter bullying, teaches social skills for dealing with bullies and promotes the development of cooperative and supportive relationships between students

Schools also need to encourage students to report incidents of bullying and to ensure that they have effective procedures in place to deal with them when they occur (Goldstein, 2013; Rigby, 2008). They need to have long-term support available for students who have been found to be targets or bullies to ensure that they continue to develop positive relationships with others. In addition, schools need to work closely with parents and other caregivers, as well as outside agencies to ensure effective 
collaboration for bullying prevention between all of those responsible for children's education and development (MoE, 2014; Thompson \& Smith, 2011).

Most importantly, schools need to implement whole-school approaches to preventing bullying, such as those employed in the following programs which operate in many schools in New Zealand. The first of these examples is Positive Behavior for Learning, which has extensive research evidence supporting its effectiveness (Coffey \& Horner, 2012), whereas the other three, Kia Kaha, Cool Schools and Restorative Practice, are widely used in New Zealand schools, with mainly anecdotal evidence of their effectiveness.

Positive Behavior for Learning proposes that all students should have access to supports in order to prevent problem behavior, including bullying. Emphasis is on labelling what the student does (eg, name-calling, intimidation) so that the behavior can be addressed. Material is available to teach staff and students: what bullying looks like; what to do when bullying is observed; how to teach others what to do; and, how to establish a positive and preventative environment that reduces bullying (Good, Mcintosh \& Gietz, 2011).

Kia Kaha (Maori for 'stay strong') is a school-based program that helps schools create environments where all members of the community feel safe, respected and valued, and where it is difficult for bullying to flourish. Kia Kaha comprises a series of programs aimed at elementary, middle and high schools that are delivered by teachers using videos and other material developed by the New Zealand Police. Kia Kaha includes resources for teachers and for parents to help children develop positive social skills with a specific focus on dealing with bullying (Raskauskas, 2007).

Cool Schools is a peer mediation program that has been operating in New Zealand since 1991 and has been implemented in nearly two thirds of schools nationwide. Cool Schools provides facilitators to go into schools to help them set up peer counseling programs (Goldstein, 2013; Thompson \& Smith, 2011). The facilitators work with teachers and volunteer students to establish sound procedures for establishing peer counseling and support throughout the school. The program aims to empower children by teaching them skills and processes to resolve conflict peacefully. They learn how to use conflict scenarios as an opportunity to build positive relationships with others. Schools implementing the program report that 80 $85 \%$ of minor disputes are settled by peer mediators helping to make the school environment (both playground and classroom) a happier, safer, more peaceful place to 
be (MoE, 2014).

Restorative practice is an approach that can be used in response to behavioral problems including bullying (Wachtel, 2013). Restorative practice teaches students positive skills for relating to others, rather than relying only on punishment.

Restorative practice proactively emphasizes building and restoring relationships in order to improve students' social and emotional learning, increase engagement with school, lessen risky behavior and enhance success at school (Thorsborne \& Blood, 2013).

The effectiveness of bullying prevention programs depends on schools having an on-going commitment to fostering a positive, inclusive and respectful school environment which values diversity, has good data systems to collect relevant information about bullying, efficient progress monitoring tools, skilled and competent staff (Bradshaw, 2015). Schools need to have on-going and embedded professional development for all staff, formal coaching and coordination supports, systems to ensure accurate implementation and sustain meaningful outcomes, effective community agency connections and ensure that teachers throughout the school employ engaging learning opportunities (MoE, 2014).

Rigby (2012) agrees that schools need to have in place a range of strategies for dealing with bullying and presents a model that has six different methods with research evidence for the effectiveness of each, and suggestions about the situations in which they should be used. The six methods are: direct sanctions; strengthening the victim; mediation; restorative practice; the support group approach; and, the method of shared concern. Schools that have teachers skilled in implementing all of these methods are clearly in a much stronger position to deal with the differing circumstances in which bullying occurs.

Schools also need to develop students' awareness of bullying and their abilities to manage social situations and relate well to each other, including the interpersonal skills involved in conflict resolution in order to deal with incidents of bullying. Through programs of social and emotional learning students need to be able to understand how their thoughts, feelings and behavior are related and how they have choices about how to respond to bullying (Orpinas \& Horne, 2010).

Most importantly, schools need to actively promote a culture of 'safe telling' (MoE, 2014). That is, all students (whether they are a target, an initiator, or a bystander) should be encouraged to disclose any bullying behavior that they see, and 
acknowledgement that they have done the right thing should be provided when they do tell. As Goodstein (2013, p. 15) suggests,

If bullied students ask for help, they should not be told to 'work it out' with the person bullying them. The power imbalance prevents them from doing so. If they had the ability to solve the problem they would not have been bullied and would not be asking for assistance. Praise these youngsters for having the courage to come forward, validate their feelings, intervene, and help in any way possible.

To promote a culture of safe telling schools should encourage two-way communication between home and school about bullying behavior, establish confidential reporting systems, ensure all students know that if they do speak up they will be listened to, and ensure that teachers take all incidents reported to them seriously and respond appropriately (Craig et al., 2007; MoE, 2014). Allen (2009) suggests that there are five phases in responding to a report of bullying. First, letting the target know that the incident will be investigated. Second, gathering information about the incident. Third, implementing an intervention. Fourth, evaluating that the intervention has worked. Fifth, following up to make that the situation has been resolved.

\section{Communities}

The communities in which schools are embedded can play an important role in the reduction of bullying, so schools need to work closely with their local communities in order to make the most of these. The most important stakeholders in these local communities are parents and caregivers of children who attend the school. Therefore, parents and other caregivers need to be involved in designing and implementing programs to prevent bullying. This should be part of the school's policy and procedures for involving parents in their children's education, both at school and at home (Hornby, 2011). Schools with effective parental involvement policies will be able to find parents willing to contribute in this way from their parent-teacher associations or parent governors. Involvement of parents in this way is one example of the community supporting schools in doing what they can to prevent bullying.

An important way in which schools can support the community's role in bullying prevention is to ensure that there is guidance and education for parents on dealing with bullying. Parents benefit from guidance on what they can do to ensure 
that their children avoid being bullied or becoming bullies and in teaching them how to react to bullying of themselves or others when it occurs. Parents need to know how to encourage their children to be empathic so they can understand what it is like to be bullied. Parents can learn how to teach children to be assertive and use appropriate social skills to deal with bullies whether they are the target or a bystander. These and other aspects of parent education on bullying are covered in an informative book by Rigby (2008) which is aimed at parents but is also useful for teachers as it delivers sound practical guidance based on theory and research on bullying.

Schools can also help parents to access counseling and support available for targets of bullying and their families in their communities (Harcourt, Jasperse \& Green, 2014). Linking parents with local support groups and directing them to useful websites and internet programs on dealing with bullying, such as, 'Success in Stages' (Evers, et al., 2007) can be very helpful to parents and other family members.

Schools can also support community agencies to promote positive interactions between children and others. For example, many children spend time outside school involved in various sporting activities, so sports organizations need to play their part in encouraging healthy competition and sporting behavior that does not tolerate bullying in any form. If the attitudes and values that children experience in sporting and other organizations in their local communities tolerates bullying then this will undermine what schools are doing to prevent bullying. So schools and parents need to monitor sports, recreational and other organizations in their communities to ensure that appropriate values are being promoted.

Most importantly, communities need to have specialists available who can help schools and families deal with bullying. For example, they may have specialist teachers or psychologists knowledgeable about effective interventions for bullying. Many local education authorities in the UK and school districts in the USA have specialists who are available to schools in their area to help them deal with cases of bullying and also to ensure that policies and procedures are in place to prevent or reduce levels of bullying. When working in this role during the 1990s Young (1998) developed a support group, or no-blame, approach to bullying, based on a solution focused theory of counseling (de Shazer, 1994), which subsequent research has shown to be very effective (Robinson \& Maines, 2008). The approach is simple and relatively easy to implement and consequently is now widely used in many countries around the world. In this approach the victim is first interviewed in order to identify 
the bully or bullies, bystanders and other children who have not been involved in the bullying. A meeting is then organized by the specialist with a group with six to ten children, including the bullies, some bystanders and others not involved in the bullying, but not the target. The group is told that $\mathrm{X}$ is unhappy at school and asked what they can do to help him or her to become happier at school. Suggestions made by the children are noted along with the names of those offering. Typically, children not involved in the bullying are the first to offer suggestions, but then the bystanders and eventually the bullies add their offers of help. Typically, at the follow-up one week later the majority of bullying situations are no longer problematic (Young, 1998). For those situations that are not resolved then schools are helped by the specialist to review the procedures they have in place to prevent bullying.

\section{Society}

Societal factors also influence the levels of bullying that are found in schools. Political, economic, cultural and religious factors play a large part in determining a particular society's or community's impact on bullying in schools and other institutions within societies. As Frey, Edstrom and Hirschstein (2010, p. 411) remind us, "Research has expanded our appreciation that bullying flourishes when social systems support it. Cross-national studies testify to the power of culture to influence bullying rates." It is clear that societal norms which support equality of opportunity and fair treatment of all members of the society are essential for achieving low levels of bullying in the various institutions with the society, especially schools. Therefore, specific legislation, codes of practice, or national guidelines on bullying need to be in place at the societal level if schools are to have a realistic chance of preventing or significantly reducing levels of bullying.

In New Zealand several government departments have collaborated with the Ministry of Education in producing an extremely useful guide to bullying prevention for schools (MoE, 2014). But this will not have the impact that it could have if the Government does not make it a statutory responsibility of schools to have a comprehensive policy on bullying which is monitored by a body such as the Education Review Office that regularly inspects schools.

Likewise, if major institutions in the society do not embody values which promote cooperation and collaboration and also do not focus on preventing bullying this makes it more difficult for schools to effectively prevent bullying. So it is 
important for governments to raise awareness of the damaging effects of bullying, mobbing and other forms of harassment in work settings as well as education settings. Recent guidelines from the New Zealand Government on preventing and responding to bullying in the workplace are an example of how this is now seen to be an important part of the issue of dealing with bullying in society (Worksafe New Zealand, 2014).

In addition, the media has an important role to play in disseminating stories on the negative effects of bullying and on the importance of developing healthy approaches to relationships. In New Zealand there have been some excellent TV adverts, sponsored by the Government, on the unacceptability of bullying and harassment and focusing on non-violent means of resolving conflicts. Because of its pervasive impact across all levels and factions of society the influence of the media in promoting anti-bullying initiatives and programs is of paramount importance.

Finally, as Rigby $(2008,2014)$ highlights, a major responsibility of societies is to ensure that organizations that provide teacher education and in-service training for teachers equip teachers with a thorough understanding of bullying and its effects, as well as with the attitudes and skills necessary to implement effective strategies to prevent bullying and to intervene with any incidents of bullying that they do encounter. Research on teachers' attitudes, knowledge and skills regarding bullying suggests that there is much work to be done in this important area (Bauman and Del Rio, 2005; Drake, Price, Telljohann \& Funk, 2003; Mishna, Scarcello, Pepler \& Wiener, 2005).

\section{Bringing about change}

In order to put into practice an ecological approach to bullying prevention, such as that described above, it is necessary to address the challenges involved in bringing about change in the ways that schools are organized and in how teachers operate within them. Fullan (1991) has suggested that, although change must be developed at the systems level it can only be achieved through the performance of individuals. In fact, Fullan, Cuttress and Kilcher (2005) have stated that, "We need to develop better individuals while we simultaneously develop better organizations and systems (p. 58)." So in order to consider how to best facilitate the changes in schools that are required in order to implement an ecological approach to bullying, it is necessary to focus on school systems, classroom teachers and, most importantly, school leaders, that is, 
school principals and other members of senior management teams. This is because, as Fullan (2002, p. 17) has stated, “... we need leaders who can create a fundamental transformation in the learning cultures of schools and the teaching profession itself." No less than this is required if schools are to significantly reduce levels of bullying and create more constructive and nurturing learning environments.

Plans should be based on recognized models for bringing about change such as the eight stage process for change developed by Kotter (2012), and its adaptation by Thorsborne \& Blood (2013), as well as the advice provided by Fullan and his colleagues, that is referred to above. An eight-step process for facilitating the changes that need to be made, based on the sources referred to above, are outlined below with a focus on what schools need to address at each step.

\section{Step 1: Making a case for change}

Staff at the school need to be convinced about the need for changes in order to more effectively prevent bullying and deal with incidents of bullying that do occur. It is helpful if the majority of staff are supportive of the need for this. It is also useful to identify potential obstacles and opportunities, and start discussions with key staff and other stakeholders, such as parents of children attending the school.

\section{Step 2: Forming an implementation team}

To lead change it is necessary to bring together a team of people with the necessary skills and influence within the school. This may include teachers and members of the school's management team as well as members of the parent association, school board, and student council (see Allen, 2009). It may involve building capacity, that is, developing new knowledge, skills, competencies and resources regarding the prevention of bullying. There also needs to be a shared identity and motivation to work together to bring about change, so the team will need to meet regularly in order to plan for implementing the change and build relationships with one another.

\section{Step 3: Creating a vision for change}

A clear vision statement can help everyone understand what is desired regarding the prevention of bullying. It may involve developing an understanding that the change process is about establishing the conditions for ongoing improvement in order to overcome barriers to change. The vision needs to be underpinned by values that the school espouses to teach students and should also be feasible, focused and flexible. The implementation team needs to develop strategies for communicating the new vision to all stakeholders in a clear and compelling way. 


\section{Step 4: Communicating the vision}

The vision of changed procedures for preventing bullying needs to be repeated frequently and powerfully, talked about at every opportunity and embedded in as much school practice and professional development as possible. Channels of communication include staff meetings, school assemblies, parent evenings, school newsletters, and the school website. Schools need to provide support for teachers to implement the changes and opportunities for any concerns to be raised in order to bring about substantial improvements.

\section{Step 5: Empowering action}

So after the new procedures for preventing bullying have been put in place ongoing checks must be made to identify potential barriers, such as whether anyone is resisting the changes or whether there are school processes or structures that are getting in its way. Removing obstacles empowers teachers to execute the vision and helps implementation of the changes. It may be necessary to make changes to school organization or provide professional learning experiences to facilitate the development of necessary skills. It is important to acknowledge the efforts of the bullying prevention implementation team and of staff who are making the changes in their classrooms and throughout the school.

\section{Step 6: Fostering short-term wins within a coherent vision}

Short-term targets on the way to implementing new procedures to prevent bullying can be created by identifying easily achievable steps that can be carried out without help from any strong critics of the change. Opportunities for sharing the success of these initiatives and rewarding the staff that have helped in achieving goals can be provided. Fostering coherence involves being clear about the big picture and how short-term successes contribute to this.

\section{Step 7: Building on the change}

Kotter (2012) argues that many change projects fail because victory is declared too soon. Early successes are only the beginning of what needs to be done to achieve long-term change and embed this in the culture of the school. Each success provides an opportunity to build on changes and identify what can be improved. After every advance it is important to analyze what went right and set goals to continue building on the momentum achieved. Otherwise schools may slip back into their traditional ways of operating. Therefore, plans must include evaluation processes and procedures and ongoing assessment using these in order to ensure that changes are being 
progressively implemented (Allen, 2009). Also, Guskey (2002) suggests that changes in teachers' attitudes and beliefs typically occur after they gain evidence that improvements have taken place, so it is important to collect data to make it clear that this is the case.

\section{Step 8: Maintaining and embedding change}

In order to achieve lasting change in the ways bullying is addressed it must become embedded in the culture of the school. Continuous efforts must be made to ensure that changes are evident in relevant aspects of school organization, in changing individuals, changing systems and in liaison with the wider community. It is important that school leaders continue to support the new procedures and that new staff and students are inducted into the school culture that now involves these changes. There must be ongoing dissemination of success stories about the new processes and procedures for addressing bullying as well as recognition of staff involved in making the changes in their classrooms and throughout the school.

\section{Conclusion}

It has been argued in this article that, in order to effectively prevent or substantially reduce bullying in schools, a systemic approach needs to be adopted with interventions organized at various levels using an ecological model. An ecological model for bullying prevention has been outlined in which strategies and interventions are suggested at the levels of teachers, schools, communities, and society. Examples of the interventions that have been found in the literature to have evidence supporting their effectiveness have been identified at each of these levels. Schools adopting an ecological model for addressing bullying need to plan for making the changes necessary to implement it successfully, including preparing for overcoming the likely barriers to bringing about the changes. Guidelines for planning such a change process have been presented. It is considered that ecological approaches such as that presented here need to be comprehensively and effectively implemented in order for bullying in schools is to be substantially reduced.

\section{References}

Allen, K. P. (2009). A bullying intervention system: Reducing risk and creating support for aggressive students. Preventing School Failure, 54(3), 199-209.

Alsaker, F. D. \& Gutzwiller-Helfenfinger, E. (2010). Social behavior and peer relationships 
of victims, bully-victims, and bullies in kindergarten. In S.R. Jimerson, S. M. Swearer \& D. L. Espelage (Eds.) (2010). Handbook of bullying in schools: An international perspective. New York, NY: Routledge, pp. 87-99.

Atkinson, M. \&, Hornby, G. (2002). Mental health handbook for schools. London, England: Routledge.

Bauman, S. \& Del Rio, A. (2005). Knowledge and beliefs about bullying in schools: Comparing pre-service teachers in the United States and the United Kingdom. School Psychology International, 26(4), 428-442.

Bradshaw, C. P. (2015). Translating research to practice in bullying prevention. American Psychologist, 70(4), 322-332.

Bronfenbrenner, U. (1979). The ecology of human development. Cambridge, MA: Harvard University Press.

Canney, C. \& Byrne, A. (2006). Evaluating Circle Time as a support to social skills development - reflections on a journey in school-based research. British Journal of Special Education, 33(1), 19-24.

Casebeer, C. M. (2012). School bullying: Why quick fixes do not prevent school failure. Preventing School Failure, 56(3), 165-171.

Coffey, J. H. \& Horner, R.H. (2012). The sustainability of schoolwide positive behavior interventions and support. Exceptional Children, 78(4), 407-422.

Couvillon, M. A. \& Ilieva, V. (2011). Recommended practices: A review of schoolwide preventative programs and strategies on cyberbullying. Preventing School Failure, 55(2), 96-101.

Craig, W., Pepler, D. \& Blais, J. (2007). Responding to bullying: what works? School Psychology international, 28(4), 465-477.

Crothers, L. M. \& Kolbert, J. B. (2010). Teachers' management of student bullying in the classroom. In S. R. Jimerson, S. M. Swearer \& D. L. Espelage (Eds.) (2010).

Handbook of bullying in schools: An international perspective. New York, NY: Routledge, pp. 535-546.

Cushman, P \& Clelland, T. (2011). A health promoting schools approach to bullying. SET: Research Information for Teachers, 3, 17-25.

de Shazer, S. (1994). Words were originally magic. New York, NY: Norton.

Drake' J. A., Price, J. H., Telljohann, S. K. \& Funk, J. B. (2003). Teacher perceptions and practices regarding school bullying prevention. Journal of School Health, 73(9), 347355. 
Drugli, M. B., Fossum, S., Larsson, B. \& Morch, W. T. (2010). Characteristics of young children with persistent conduct problems 1 year after treatment with the Incredible Years program. European Child and Adolescent Psychiatry, 19, 559-565.

Durlak, J. A., Weissberg, R. P., Dymnicki, A. B., Taylor, R. D. \& Schellinger, K. B. (2011). The impact of enhancing students' social and emotional learning: A meta-analysis of school-based universal interventions. Child Development, 82, 405-432.

Elliot, G.P. (2003) School Mobbing and Emotional Abuse. New York, NY: Brunner.

Espelage, D. L. \& Swearer, S. M. (2010). A social-ecological model for bullying prevention and intervention: Understanding the impact of adults in the social ecology of youngsters. In S. R. Jimerson, S. M. Swearer \& D. L Espelage (Eds.) (2010). Handbook of bullying in schools: An international perspective. New York, NY: Routledge, pp. 61-72.

Evers, K. E., Prochaska, J. O., Van Marter, D. F., Johnson, J. L. \& Prochaska, J. M. (2007). Transtheoretical-based bullying prevention effectiveness trials in middle schools and high schools. Educational Research, 49(4), 397-414.

Fergusson, D. M., Horwood, L. J. \& Stanley, L. (2013). A preliminary evaluation of the Incredible Years teacher program. New Zealand Journal of Psychology, 42(2), 51-56.

Frey, K. S., Edstrom, L. V. \&, Hirschstein, M. K. (2010). School bullying: A crisis or an opportunity. In S. R. Jimerson, S. M. Swearer \& D. L. Espelage (Eds.) (2010). Handbook of bullying in schools: An international perspective. New York, NY: Routledge, pp. 403-415.

Fullan, M. G. (1991). The new meaning of educational change. New York, NY: Teachers College Press.

Fullan, M. (2002). The change leader. Educational Leadership, 59(8), 16-20.

Fullan, M., Cuttress, C. \& Kilcher, A. (2005). 8 forces for leaders of change. Journal of Staff Development, 26(4), 54-64.

Garandeau, C. F., Wilson, T. \& Rodkin, P. C. (2010). The popularity of elementary school bullies in gender and racial context. In S. R. Jimerson, S. M. Swearer \& D. L. Espelage (Eds.) (2010). Handbook of bullying in schools: An international perspective. New York, NY: Routledge, pp 119-136.

Good, C., Mcintosh, G. K. \& Gietz, C. (2011). Integrating bullying prevention into schoolwide Positive Behavior Support. Teaching Exceptional Children, 44(1), 48-56.

Goodstein, P. K. (2013). How to stop bullying in classrooms and schools: use social architecture to prevent, lessen and end bullying. New York, NY: Routledge. 
Guskey, T. R. (2002). Professional development and teacher change. Teachers and Teaching; theory and practice, 8(3), 381-391.

Hamarus, P. \& Kaikkonen, P. (2008). School bullying as a creator of pupil peer pressure. Educational Research, 50(4), 333-345.

Harcourt, S. \& Green, V. A. (2013). Bullying in New Zealand Schools. SPANZ: The journal of the secondary principals association of New Zealand, December, 14-18.

Harcourt, S., Jasperse, M. \& Green, V.A. (2014). “We were sad and we were angry' : A systematic review of parents' perspectives on bullying. Child Youth Care Forum, 43, 373-391.

Hartley, M. T., Bauman, S., Nixon, C. L. \& Davis, S. (2015). Comparative study of bullying victimization among students in general and special education. Exceptional Children, 81(2), 176-193.

Hornby, G. (2011). Parental involvement in childhood education: Building effective schoolfamily partnerships. New York, NY: Springer.

Hymel, S. \& Swearer, S. M. (2015). Four decades of research on school bullying: An introduction. American Psychologist, 70(4), 293-299.

Jimerson, S. R., Swearer, S. M. \& Espelage, D. L. (Eds.) (2010). Handbook of bullying in schools: An international perspective. New York, NY: Routledge.

Kotter, J. P. (2012). Leading change. Cambridge, MA: Harvard Business Review Press.

Krug, E. G., Dahlberg, L., Mercy, J. A., Zwi, A. B. \& Lozano, R. (2002). World report on violence and health. Geneva, Switzerland: World Health Organization.

Lawner, E. K. \& Terzian, M. A. (2013). What works for bullying programs. Bethesda, MD: Child Trends.

Merrell, K. W., Gueldner, B. A., Ross, S. W., \& Isava, D. M. (2008). How effective are school bullying intervention programs? A meta-analysis of intervention research. School Psychology Quarterly, 23(1), 26-42.

Miller, D \& Moran, T. (2007). Theory and practice in self-esteem enhancement: Circle Time and efficacy-based approaches - a controlled evaluation. Teachers and Teaching: Theory and Practice, 13(6), 601-615.

Mishna, F., Scarcello, I., Pepler, D. \& Wiener, J. (2005). Teachers' understanding of bullying. Canadian Journal of Education, 28(4) 718-738.

MoE (2014). Bullying prevention and response: a guide for schools. Wellington, New

Zealand: Ministry of Education. Retrieved from: http://pb4l.tki.org.nz/Deter-bullying

Mosely, J. (1996). Quality Circle Time in the elementary classroom: our essential guide to 
enhancing self-esteem, self-discipline and positive relationships. London, England: LDA.

Nansel, T. R., Overpeck, M., Pilla, R. S., Ruan, W. J., Simons-Morgan, B. \& Scheidt, P. (2001). Bullying behaviors among US youth: Prevalence and association with psychosocial adjustment. Journal of the American Medical Association, 285, 20942100.

Olweus, D. (1993). Bullying at school: What we know and what we can do. Oxford, England: Blackwell.

Olweus, D. (2010). Understanding and researching bullying: Some critical issues. In S.R. Jimerson, S. M. Swearer \& D. L Espelage (Eds.) (2010). Handbook of bullying in schools: An international perspective. New York, NY: Routledge, pp. 9-33.

Orpinas, P \&, Horne, A. M. (2010). Creating a positive school climate and developing social competence. In S. R. Jimerson, S. M. Swearer \& D. L. Espelage (Eds.) (2010). Handbook of bullying in schools: An international perspective. New York, NY: Routledge, pp. 49-59.

Pidano, A. E. \& Allen, A. R. (2015). The Incredible Years Series: A review of the independent research base. Journal of Child and Family Studies, 24, 1898-1916.

Raskauskas, J. (2007). Evaluation of the Kia Kaha anti-bullying program for students in years 5 -8. Wellington, New Zealand: New Zealand Police.

Rigby, K. (2008). Children and bullying: How parents and educators can reduce bullying at school. Malden, MA: Blackwell.

Rigby, K (2011). What can schools do about cases of bullying? Pastoral Care in Education, 29(4), $273-285$.

Rigby, K. (2012). Bullying interventions in schools: Six basic approaches. Chichester, England: Wiley/Blackwell.

Rigby, K. \& Smith, P. K. (2011). Is school bullying really on the rise? Social Psychology of Education, 14, 441-455.

Robinson, G., \& Maines, B. (2008). Bullying: A complete guide to the support group method. London, England: Sage.

Smith, P. K., Pepler, D. \& Rigby, K. (Eds.) (2004). Bullying in schools: How successful can interventions be? Cambridge, England: Cambridge University Press.

Smith, P.K. \&, Sharp, S. (Eds.) (1994). School bullying: Insights and perspectives. London, England: Routledge.

Smith, P. K. \& Slonje, R. (2010). Cyberbullying: The nature and extent of a new kind of 
bullying, in and out of school. In S. R. Jimerson, S. M. Swearer \& D. L. Espelage (Eds.) (2010). Handbook of bullying in schools: An international perspective. New York, NY: Routledge, pp. 249-262.

Snakenborg, J., Acker, R. V. \& Gable, R. A. (2011). Cyberbullying: Prevention and intervention to protect our children and youth. Preventing School Failure, 55(2), 8895.

Thompson, F., \& Smith, P. K. (2011). The use and effectiveness of anti-bullying strategies in schools. Research Report DFE-RR098. London: HMSO.

Thorsborne, M. \& Blood, P. (2013). Implementing restorative practices in schools: a practical guide to transforming school communities. London, England: Jessica Kingsley.

Ttofi, M. M. \& Farrington, D. P. (2011). Effectiveness of school-based programs to reduce bullying: a systematic and meta-analytic review. Journal of Experimental Criminology, 7, 27-56.

Wachtel, T. (2013). Dreaming of a new reality: How restorative practices reduce crime and violence, improve relationships and strengthen civil society. Bethlehem, PA: The Piper's Press.

Webster-Stratton, C. \& Reid, M. J. (2010). The Incredible Years Parents, Teachers, and Children Training Series: A multifaceted treatment approach for young children with conduct disorders. In J. R. Weisz \& A. E. Kazdin (eds.). Evidence-based psychotherapies for children and adolescents (second edition). New York, NY: Guilford.

Worksafe New Zealand (2014). Preventing and responding to workplace bullying: Best practice guidelines. Wellington, New Zealand: New Zealand Government.

Young, S. (1998). The support group approach to bullying in schools. Educational Psychology in Practice, 14(1), 32-39.

\section{Hornby notes}

Garry worked as a mainstream and special education teacher and as an educational psychologist before lecturing in educational psychology and special education in England, Barbados and New Zealand. He has published over 100 journal articles and book chapters and published thirteen books, the most recent being on 'Parental involvement in childhood education (2011)' and 'Inclusive special education (2014)'. 
He most recently spent 12 years as Professor of Education at the University of Canterbury in New Zealand, and has now retired to live in Barbados. 